\title{
A neurotoxic regimen of methamphetamine exacerbates the febrile and neuroinflammatory response to a subsequent peripheral immune stimulus
}

\author{
Jessica B Buchanan*, Nathan L Sparkman, Rodney W Johnson
}

\begin{abstract}
Methamphetamine (MA) use is associated with activation of microglia and, at high doses, can induce neurotoxicity. Given the changes in the neuroinflammatory environment associated with MA, we investigated whether MA administration would interfere with the thermoregulatory and neuroinflammatory response to a subsequent peripheral immune stimulus. C57BL6/J mice were given four i.p. injections of either $5 \mathrm{mg} / \mathrm{kg} \mathrm{MA}$ or saline at two hour intervals. Twenty-four hours following the first MA injection, mice were given $100 \mu \mathrm{g} / \mathrm{kg}$ LPS or saline i.p. and blood and brains were collected. Here we report that mice exposed to MA developed higher fevers in response to LPS than did those given LPS alone. MA also exacerbated the LPS-induced increase in central cytokine mRNA. MA alone increased microglial Iba1 expression and expression was further increased when mice were exposed to both MA and LPS, suggesting that MA not only activated microglia but also influenced their response to a peripheral immune stimulus. Taken together, these data show that MA administration exacerbates the normal central immune response, most likely by altering microglia.
\end{abstract}

\section{Background}

Methamphetamine is a popular drug of abuse that has several central effects and is associated with an increased prevalence of HIV infection, hepatitis B and $\mathrm{C}$, fungal infections, and possibly others [1-4]. Given the popularity of MA, it is becoming increasingly important to understand the effects of MA use on host responses. Among some of its detrimental effects, MA exposure has been associated with oxidative stress and the production of reactive oxygen and nitrogen species $[5,6]$, neurotoxicity $[7,8]$, and an increase in microglial activation and astrocytes, leading to the production of proinflammatory cytokines $[9,10]$. Long-term MA users show prominent microglial activation in certain brain regions that are sometimes apparent almost 2 years after MA use had ceased [9]. MA-induced microglial activation has also been shown in animals given high doses of MA

\footnotetext{
* Correspondence: jessieb@illinois.edu
Laboratory of Integrative Immunology and Behavior, Department of Animal

* Correspondence: jessieb@illinois.edu
Laboratory of Integrative Immunology and Behavior, Department of Animal Sciences, University of Illinois Urbana-Champaign, 1207 W. Gregory Drive, Urbana, IL 61801, USA
}

[11-13] and there is evidence that this activation remains apparent up to seven days after treatment [10]. Both high and low doses of MA can induce inflammatory cytokines such as tumor necrosis factor $\alpha$ (TNF $\alpha)$, interleukin-1 $\beta$ (IL-1 $\beta$ ), and IL- 6 in the brains of rodents [14-17]. Indeed, high-dose MA administration increased TNF $\alpha$ protein in the straitum three days after treatment [18] and in the hippocampus seven days after treatment [10].

Peripherally, acute and chronic MA administration have been shown to reduce the number of leukocytes as well as NK cell activity of splenic lymphocytes [19]. Chronic MA administration reduced Con A-induced $\mathrm{T}$-cell proliferation as well as IL- 2 and IFN $\gamma$ production in mouse splenocytes [20], and a binge dosing regimen suppressed the peripheral immune response to fungal infection [21]. MA has also been shown to decrease IL-1 production by splenocytes in mice [22] and reduce IFN $\gamma$ and IL-10 while increasing IL-4, MCP-1, and TNF $\alpha$ in plasma [12]. Taken together, these data suggest that MA alters the production of both inflammatory and 
anti-inflammatory cytokines in the periphery while inducing a heightened inflammatory environment in the brain. This MA-induced increase in brain inflammation has the potential to influence the body's response to a subsequent immune stimulus.

While there are many studies concerning the consequences of MA use alone, little is known concerning the neuroinflammatory consequences of MA use and subsequent peripheral immune stimulation. Infection in the periphery results in the production of inflammatory cytokines which, through neural and humoral pathways, induce glial cells in discrete brain regions to produce the same inflammatory cytokines $[23,24]$. It is this central production of inflammatory cytokines that is responsible for inducing sickness behavior including fever, anorexia, as well as reduced locomotor and social behaviors. Excessive production of inflammatory cytokines has been shown to produce severe behavioral deficits and promote neurotoxicity [25]. Thus, circumstances that enhance inflammatory cytokine production by microglial cells, such as MA use, are likely to lead to pronounced and prolonged behavioral deficits that are not conducive to health and recovery.

We have previously shown that repeated administration of low-dose MA attenuated both the febrile and neuroinflammatory response to a subsequent injection of lipopolysaccharide (LPS) in mice [26]. The attenuated response appeared to be related to a MA-associated alteration in the microglial response. Mice exposed to five days of consecutive low-dose MA administration showed decreased microglial activation when given a subsequent injection of LPS compared to mice given LPS alone. Given this decreased microglial activity, we concluded that the MA-induced attenuation of the febrile and neuroinflammatory response was due to an inability of microglia to respond to LPS. Because of this, the present study utilized a MA administration schedule expected to activate microglia [7,13]. We hypothesized that this MA schedule would activate microglia and exacerbate the sickness and neuroinflammatory response to LPS. Here we report that exposure to MA enhances the LPS-induced fever response that is paralleled by increased microglial staining and a dramatic increase in inflammatory cytokine mRNA expression in the brain.

\section{Methods}

Animals and surgery

Adult (3-5 mo) male C57BL/6 mice from The Jackson Laboratories were used. Mice were housed in polypropylene cages and maintained at $23^{\circ} \mathrm{C}$ under a diurnal $12 \mathrm{~h}$ light-dark cycle (lights on at 0700) with ad libitum access to water and rodent chow. To allow for continuous monitoring of body temperature $(\mathrm{Tb})$ and locomotor activity, mice were anesthetized with an intraperitoneal (i.p.) injection of ketamine and xylazine (100 and $10 \mathrm{mg}$, respectively) and implanted with a biotelemetry device (E-mitter, Mini Mitter, Bend, OR). Briefly, a midline abdominal incision was made $1 \mathrm{~cm}$ below the diaphragm and the E-mitter was positioned in the abdominal cavity along the sagittal plane. The muscle wall was sutured with chromic gut and the skin sutured with silk surgical thread. Following surgery, mice were individually housed and each cage was placed on a receiver board (model ER-4000 Receiver, Mini Mitter). Data was collected every 5 min utilizing the Vital View data acquisition system (Mini Mitter Co., Bend, $\mathrm{OR})$. $\mathrm{Tb}$ and locomotor activity were monitored from the time of implantation until the end of the experiment. Mice were allowed at least 7 days to recover from surgery before any experimental procedures took place. All procedures were in accordance with the National Institutes of Health Guidelines for the Care and Use of Laboratory Animals and were approved by the University of Illinois Institutional Animal Care and Use Committee.

\section{Drugs}

MA [(+)-Methamphetamine hydrochloride (Sigma, Cat \# M-8750)] was dissolved in sterile saline and injected i.p. at a dose of $5 \mathrm{mg} \mathrm{MA} \cdot \mathrm{HCl} / \mathrm{kg}$ body weight, four times at $2 \mathrm{~h}$ intervals. This dosing schedule was based on reports by Thomas and Khun $[7,13]$ that showed the schedule induced microglial activation. Escherichia coli LPS (serotype 0127:B8, Sigma) was dissolved in sterile saline and injected i.p. at $100 \mu \mathrm{g} / \mathrm{kg}$ body weight, a dose that reliably causes fever in mice. Both MA and LPS were diluted such that each dose was equivalent to an injection volume of $0.01 \mathrm{mg} / \mathrm{g}$. Control mice received an equivalent volume of saline.

\section{Experimental design \\ $M A$ and LPS}

To investigate if MA administration affects the inflammatory response to peripheral immune activation, mice received four i.p. injections of either $5 \mathrm{mg} / \mathrm{kg}$ MA or saline at $2 \mathrm{~h}$ intervals. Twenty-four hours after the first MA injection, mice received i.p. injections of either LPS $(100 \mu \mathrm{g} / \mathrm{kg})$ or saline and $\mathrm{Tb}$ and locomotor activity were monitored for the next $24 \mathrm{~h}$. Mice were then killed by $\mathrm{CO}_{2}$ asphyxiation and blood and brains were collected for cytokine measurement. To measure cytokines at a time point when mice were actively sick, a separate group of mice not implanted with E-mitters was subjected to the same experimental protocol and killed at $4 \mathrm{~h}$ post-LPS.

\section{Cytokine mRNA measurement by quantitative real-time PCR}

Total hypothalamic RNA was isolated using the Arcturus PicoPure ${ }^{\text {tM }}$ RNA isolation kit as described by the 
manufacturer. DNase treatment was performed on a PicoPure column with a Qiagen RNase-free DNase set (Qiagen, Valenica, CA). RNA from all other regions was isolated using the Tri Reagent protocol (Sigma, St. Louis, MO). A QuantiTect Reverse Transcription Kit (Qiagen, Valencia, CA) was used for cDNA synthesis with integrated removal of genomic DNA contamination according to the manufacturer's protocol and previously described [26]. Quantitative real-time PCR was performed using the Applied Biosystems (Foster, CA) Assay-on Demand Gene Expression protocol as previously described [26]. In brief, cDNA was amplified by PCR where a target cDNA (IL-6, Mm00446190_m1; IL$1 \beta, M m 00434228 \_m 1 ; T N F \alpha, M m 00443258 \_m 1$; and CD68, Mn00839636_gl) and a reference cDNA (glucose3 phosphate dehydrogenase, Mm99999915_g1) were amplified simultaneously using an oligonucleotide probe with a 5 ' fluorescent reporter dye (6-FAM) and a 3' quencher dye (NFQ). PCR reactions were performed in triplicate under the following conditions: $50^{\circ} \mathrm{C}$ for 2 min, $95^{\circ} \mathrm{C}$ for $10 \mathrm{~min}$, followed by 40 cycles of $95^{\circ} \mathrm{C}$ for $15 \mathrm{sec}$, and $60^{\circ} \mathrm{C}$ for $1 \mathrm{~min}$. Fluorescence was determined on an ABI PRISM 7900HT-sequence detection system (Perkin Elmer, Forest City, CA). Data were analyzed using the comparative threshold cycle $(\mathrm{Ct})$ method, and results are expressed as fold difference.

\section{Plasma cytokines}

Plasma samples were assayed for IL- $1 \beta$, TNF $\alpha$, IL- 6 , and IL-10 using a multiplex bead-based immunoassay kit combined with a Cytokine Reagent kit as described by the manufacturer (Bio-Rad, Hercules, CA). The multiplex assay was sensitive to $<3 \mathrm{pg} / \mathrm{ml}$ for IL- $1 \beta$, TNF $\alpha$, IL-10, and IL-6. The inter-assay and intra-assay coefficients of variation were $<8 \%$.

\section{Immunohistochemical staining and quantification}

A separate group of mice was exposed to the MA regimen and then given either $100 \mu \mathrm{g} / \mathrm{kg}$ of LPS or saline. Four hours after i.p. injection of LPS, mice were killed by $\mathrm{CO}_{2}$ asphyxiation and transcardially perfused with heparinized saline followed by $4 \%$ paraformaldehyde, and brains were removed. Brains were blocked in 3 parts (rostral, mid and caudal), postfixed over 2 days in $4 \%$ paraformaldehyde, and paraffin embedded. Coronal sections $(4 \mu \mathrm{m})$ were cut on a microtome and every $10^{\text {th }}$ section was stained for Iba1 (ionized calcium binding adapter molecule 1; Wako Chemicals USA, Richmond, $\mathrm{VA}$ ) at the level of the striatum (Bregma $-0.82 \mathrm{~mm}$ ) and at the hippocampus (Bregma $-2.18 \mathrm{~mm}$ ). Sections were dewaxed and rehydrated through xylene and alcohols and were incubated in citrate buffer, $\mathrm{pH} 6$, and microwaved for $10 \mathrm{~min}$. Endogenous peroxidase was eliminated by incubating sections in $3 \% \mathrm{H}_{2} \mathrm{O}_{2}$ /methanol for
15 min. Sections were washed in PBS and blocked with $5 \%$ normal goat serum in PBS before overnight incubation at $4^{\circ} \mathrm{C}$ with the primary antibody $(1: 1200)$ in $5 \%$ blocking serum. The sections were washed, and then incubated with biotinylated goat anti-rabbit antibody (Vector Laboratories, Burlingame, CA) for $1 \mathrm{~h}$. Staining was visualized using the $\mathrm{ABC}$ method and 3,3'-diaminobenzidine and sections were counterstained with hemotoxylin. Isotype-matched IgG was used as negative control. Immunostaining was visualized using an Optronix Microfire camera (model S99808, Goleta, CA) attached to a Zeiss Axio Imager A.1 microscope (Gottingen, Germany). The numbers of Iba1-positive cells were counted by two blind observers and verified using ImageJ http://rsbweb.nih.gov/ij/. The number of positive cells was determined in both hemispheres of a given section using a total of four sections per mouse and expressed as number of cells per $100 \mu \mathrm{m}^{2}$.

\section{Data Collection and Analysis}

$\mathrm{Tb}$ and locomotor activity data were collected every $5 \mathrm{~min}$ and averaged over 30 minutes. Change in locomotor activity following injection was calculated as the $30-\mathrm{min}$ average at each time point minus the 30 -min average at time 0 (the time of injection). $\mathrm{Tb}$ and locomotor activity data from LPS experiments were subjected to repeatedmeasures ANOVA in which Time was a within-subjects measure and MA (MA or Saline) and LPS (LPS or Saline) were between-subjects measures. Central cytokine mRNA levels and peripheral cytokines were analyzed using two-way ANOVA (MA $\times$ LPS). When ANOVAs revealed a significant effect of main factors or main factor interactions, differences in treatment group means were tested using Fisher's least-significant differences. All data are presented as means \pm SEM.

\section{Results}

\section{MA administration}

Figure $1 \mathrm{~A}$ and $1 \mathrm{~B}$ shows $\mathrm{Tb}$ and changes in locomotor activity during MA administration. As expected, there was a main effect of MA for Tb $[\mathrm{F}(1,30)=8.022$, $\mathrm{p}<$ $0.01]$ and locomotor activity $[\mathrm{F}(1,30)=17.27, \mathrm{p}<$ $0.001]$ whereby MA increased both $\mathrm{Tb}$ and locomotor activity compared to saline.

\section{Methamphetamine administration enhances LPS-induced fever}

We next investigated if MA administration would interfere with the febrile response to a peripheral immune stimulus (LPS, $100 \mu \mathrm{g} / \mathrm{kg}$ ). Mice received four i.p. injections of MA $(5 \mathrm{mg} / \mathrm{kg})$ or saline and then were given i. p. LPS or saline $24 \mathrm{~h}$ after the first MA injection. LPS induced an increase in $\mathrm{Tb}$ that peaked 3-4 $\mathrm{h}$ after injection (Figure $2 \mathrm{~A}$ ). For $\mathrm{Tb}$, there were main effects of LPS 


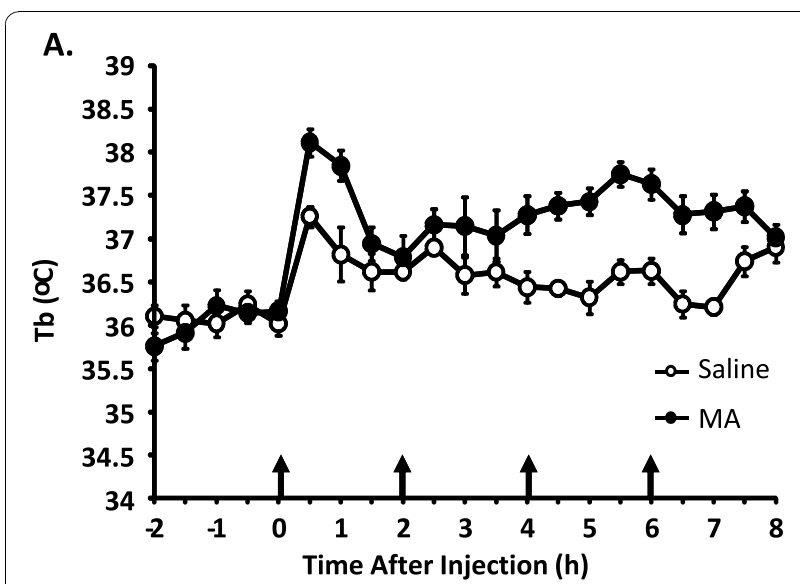

B.

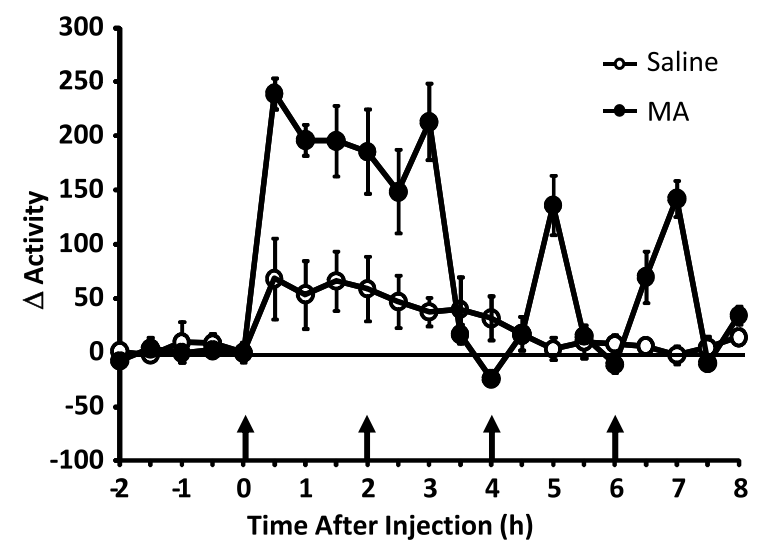

Figure 1 Body temperature and locomotor activity during methamphetamine administration. Effect of 4 i.p. injections of MA on $\mathrm{Tb}(\mathrm{A})$, and change in locomotor activity (B) Open symbols represent saline controls and closed symbols represent MA administration ( $\mathrm{n}=16-18$ per group). Activity data is presented as 30 minute averages from time of injection. Arrows indicate injection times.

$[\mathrm{F}(1,30)=25.459, \mathrm{p}<0.001]$ and $\mathrm{MA}[\mathrm{F}(1,30)=6.139$, $\mathrm{p}<0.02]$. There was also a trend toward a MA $\times$ LPS interaction $(p=0.06)$ where animals exposed to MA had higher fevers in response to LPS than those given LPS alone. Indeed, the Tb of mice receiving LPS alone peaked at $1.4^{\circ} \mathrm{C}$ compared to $\mathrm{Tb}$ at time 0 while those exposed to MA before LPS administration had a peak fever of $2.2^{\circ} \mathrm{C}$.

As expected, there was a main effect of LPS for locomotor activity $[\mathrm{F}(1,30)=12.012, \mathrm{p}<0.01]$ where LPS decreased locomotor activity compared to saline. This LPS-induced decrease in locomotor activity was not influenced by prior exposure to MA (Figure 2B).

\section{Methamphetamine administration exacerbates the} neuroinflammatory response to LPS

To examine the neuroinflammatory response to LPS when mice were actively sick, animals were given four

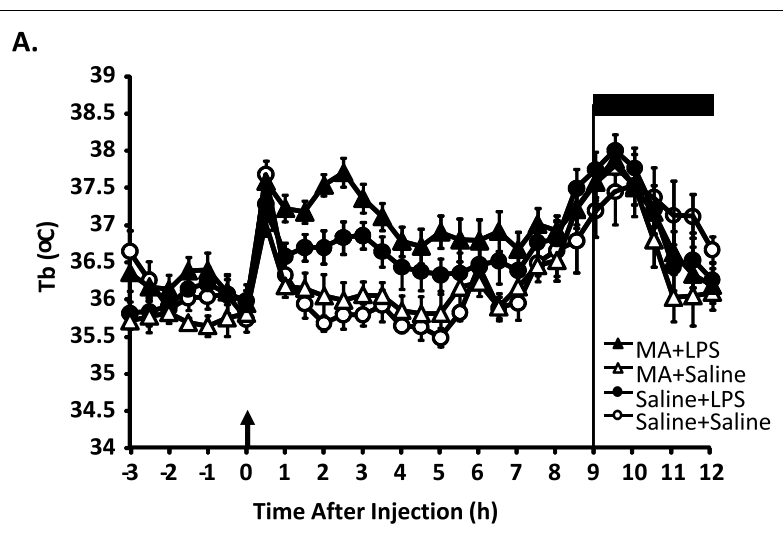

B.

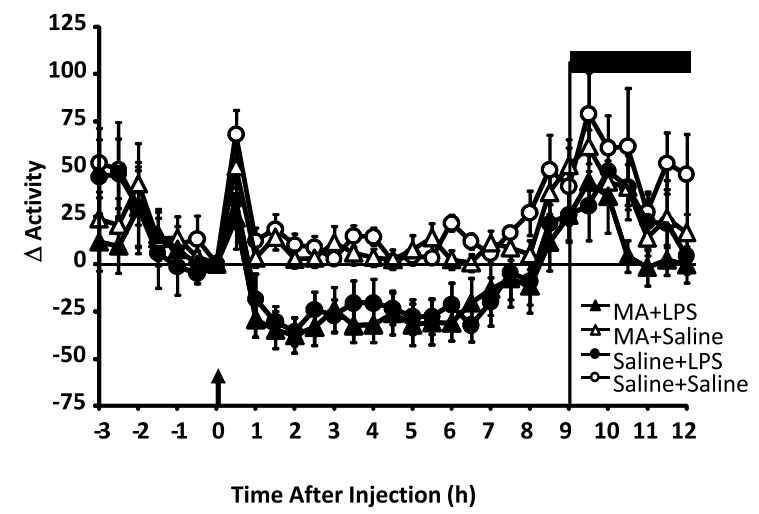

Figure 2 Body temperature and locomotor response to LPS in mice exposed to methamphetamine. $\mathrm{Tb}(\mathrm{A})$ and locomotor activity (B) after LPS or saline in mice exposed to MA. Mice were exposed to 4 i.p. injections of 0 or $5 \mathrm{mg} / \mathrm{kg} \mathrm{MA}$ and then injected with $100 \mu \mathrm{g} / \mathrm{kg}$ LPS or saline, $24 \mathrm{~h}$ after the first MA injection. Open circles represent saline + saline administration, open triangles represent saline + MA administration, closed circles represent saline + LPS administration and closed triangles represent mice MA + LPS administration ( $n=6-10$ per group). Arrow indicates time of injection; dark bar indicates lights off.

injections of $5 \mathrm{mg} / \mathrm{kg}$ MA or saline, followed by LPS or saline $24 \mathrm{~h}$ after the first MA injection. Mice were killed at $4 \mathrm{~h}$ post-LPS and blood and brains were collected. To examine the global effects of MA and LPS in the brain, five regions were collected: the hypothalamus and hippocampus, which are intimately involved in the sickness response; the striatum and cortex, regions sensitive to $\mathrm{MA}$; and the cerebellum, a region important for motor control. Figure $3 \mathrm{~A}, \mathrm{~B}$ and $\mathrm{CC}$ shows changes in inflammatory cytokine mRNA in the five brain regions studied. MA alone increased IL-6 mRNA levels in the hypothalamus (main effect of MA, $\mathrm{p}<0.01$ ) and TNF $\alpha$ mRNA in the hippocampus and striatum (main effect of MA, p < 0.01 and $\mathrm{p}<0.001$, respectively). This trend was also observed in the other regions, although it was not statistically significant. The MA-induced increase in TNF $\alpha$ mRNA was most apparent in the striatum, where MA 
A. IL-1 $\beta$

Hypothalamus Hippocampus Striatum Cortex Cerebellum

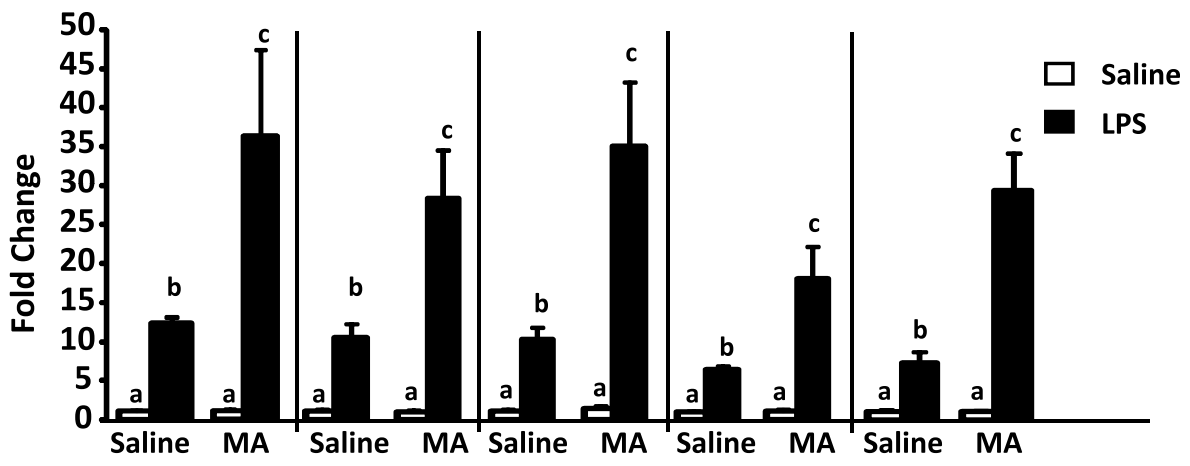

B. IL-6

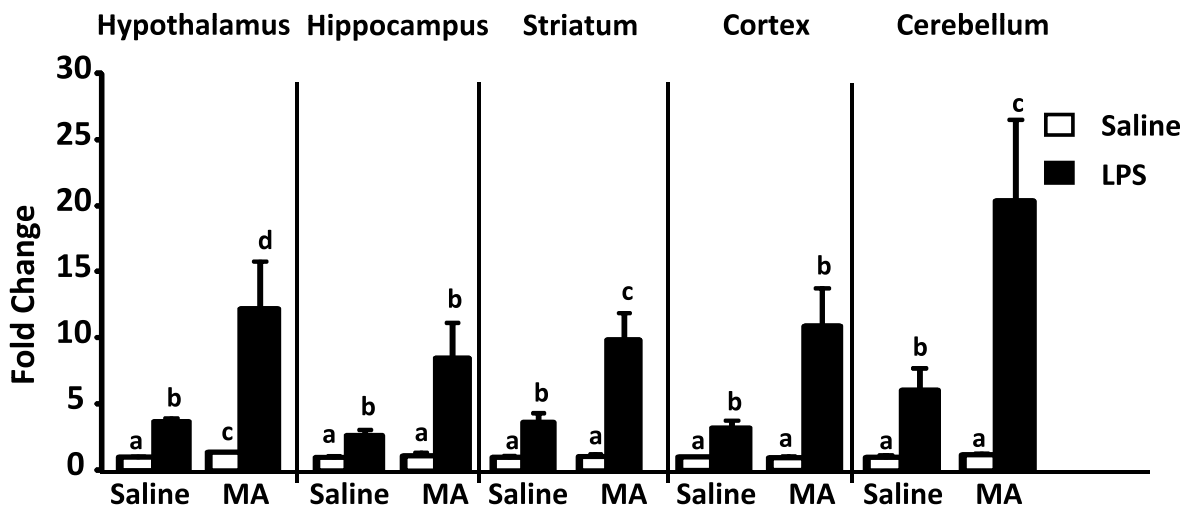

C. TNF $\alpha$

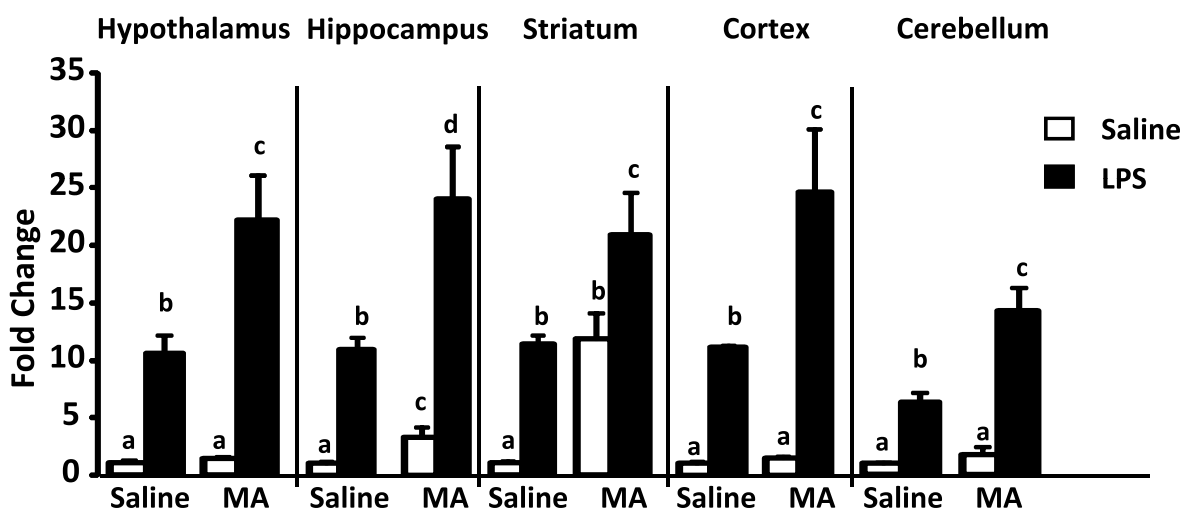

Figure 3 Cytokine mRNA expression $4 \mathbf{h}$ after LPS in mice exposed to methamphetamine. IL-1 $\beta$ (A), IL-6 (B), and TNF $\alpha$ (C) mRNA expression in the hypothalamus, hippocampus, striatum, cortex, and cerebellum in mice exposed to MA. Mice exposed to MA were given LPS or MA and brains were collected $4 \mathrm{~h}$ post-LPS ( $n=4$ per group). Means with different letters are at least $p<0.05$ different from each other.

increased TNF $\alpha$ mRNA levels to the same extent as that of LPS alone (Figure 3C).

LPS increased inflammatory cytokine mRNA in all brain regions examined. For IL- $1 \beta$ mRNA (Figure 3A), there was a MA $\times$ LPS interaction whereby MA exposure exacerbated the LPS-induced increase in the hypothalamus $[\mathrm{F}(1,12)=6.545, \mathrm{p}<0.03]$, hippocampus $[\mathrm{F}(1,12)=7.972, \mathrm{p}<0.02]$, striatum $[\mathrm{F}(1,12)=8.385$, $\mathrm{p}<0.02)]$, cortex $[\mathrm{F}(1,12)=8.242, \mathrm{p}<0.02)]$, and cerebellum $[\mathrm{F}(1,12)=19.873, \mathrm{p}<0.001]$. A similar interaction was seen for IL-6 mRNA (Figure 3B) in the hypothalamus $[\mathrm{F}(1,12)=5.232, \mathrm{p}<0.05]$, striatum $[\mathrm{F}$ $(1,12)=8.169, \mathrm{p}<0.02]$, cortex $[\mathrm{F}(1,12)=6.946, \mathrm{p}<$ $0.03]$, and cerebellum $[\mathrm{F}(1,12)=4.993, \mathrm{p}<0.05]$. The MA $\times$ LPS interaction was also apparent for TNF $\alpha$ mRNA (Figure 3C) in the hypothalamus $[F(1,12)=$ 
6.942, $\mathrm{p}<0.03]$, hippocampus $[\mathrm{F}(1,12)=5.14, \mathrm{p}<$ $0.05]$, cortex $[\mathrm{F}(1,12)=5.673, \mathrm{p}<0.04]$ and cerebellum $[\mathrm{F}(1,12)=9.964, \mathrm{p}<0.01]$

\section{Methamphetamine administration increases microglial expression of lba1}

Based on the results of Thomas and Kuhn (2005), the MA dosing regimen used here was expected to activate microglia. We therefore investigated if MA administration altered the microglial response to LPS. Iba1 is specifically expressed in microglia and expression is particularly enhanced under pathological conditions [27-30]. MA exposure increased Iba1 expression in both the striatum and the hippocampus (main effect of MA, $\mathrm{p}<0.001$ ). This MA-related increase was also observed for CD68 mRNA in the hypothalamus, hippocampus, striatum, and cerebellum (data not shown). Furthermore, while there were main effects for MA and LPS in both the hippocampus and straitum (Figure 4A and 4B), there was a MA $\times$ LPS interaction in the striatum [F $(1,12)=5.386, \mathrm{p}<0.05]$ whereby Iba1 expression was further increased when MA exposure was paired with LPS administration.

\section{Methamphetamine influences plasma cytokines}

To investigate the peripheral cytokine response to LPS in MA-exposed mice, blood was collected $4 \mathrm{~h}$ postLPS and plasma cytokines were measured (Table 1). LPS increased plasma IL-10 levels regardless of MA exposure (main effect of LPS, $\mathrm{p}<0.01$ ). For IL-1 $\beta$ there was a significant MA $\times$ LPS interaction whereby MA alone increased IL-1 $\beta$ while MA plus LPS effectively abolished the LPS-induced increase [F $(1,12)=10.145, \mathrm{p}<0.01]$. A similar MA-related inhibition of the LPS-induced increase was seen for TNF $\alpha$ but was not statistically significant $(\mathrm{p}=0.08)$. The opposite trend was observed for plasma IL-6. LPS increased IL-6 in both MA-exposed and non-exposed mice (main effect of LPS, $\mathrm{p}<0.01$ ), but there was a trend towards a MA $\times$ LPS interaction $(\mathrm{p}=0.08)$ where mice exposed to MA had increased plasma levels of IL- 6 than did those given LPS alone. These data suggest that exposure to MA can alter the peripheral inflammatory cytokine response to LPS.

\section{Discussion}

MA is a popular drug of abuse that has several central effects and prolonged, or heavy usage can activate the primary inflammatory cells of the brain; microglia. Because MA has been shown to heighten the inflammatory environment of the brain, we hypothesized that MA administration would exacerbate LPS-induced sickness behavior as well as the neuroinflammatory cytokine response. Using a MA regimen expected to activate microglia, we demonstrate that MA administration enhanced LPS-induced fever, and this response was paralleled by a dramatic increase in central cytokine mRNA expression $4 \mathrm{~h}$ post-LPS. Moreover, the MA-induced increase in microglial Iba1 expression was even greater in mice exposed to both MA and LPS, suggesting that MA can alter the response of microglia to a subsequent peripheral immune stimulus.

MA-induced microglial activation has been demonstrated in animals given high doses of MA [11-13] and is associated with the production of inflammatory cytokines in the brains of rodents [14-17]. However, little is known concerning the neuroinflammatory consequences of such MA use on a subsequent peripheral immune stimulus. We therefore utilized a MA regimen demonstrated to activate microglia and measured Iba1 expression $4 \mathrm{~h}$ after LPS. Microglial Iba1 expression was significantly increased in animals exposed to MA. While MA appeared to increase expression of microglial markers globally, the effect was most apparent in the striatum. Given that MA can greatly affect dopamine nerve endings in the striatum, the robust MA-related staining observed in this region is unsurprising. More interestingly, when LPS was given to mice exposed to MA, Iba1 expression was further increased in this region. This MA-related increase in Iba1 expression was paralleled by increased expression in inflammatory cytokines in brain $4 \mathrm{~h}$ after LPS. This suggests that the current model of MA exposure not only activates microglia, but alters them such that they respond more when the peripheral immune system is stimulated.

MA-related microglial responses appear to depend on the dose and schedule used. For instance, there are several reports demonstrating that chronic low-dose MA can attenuate the neurotoxic effects of [31-35], and the microglial response to [13], a subsequent high-dose MA challenge. Our previous study found that while a single administration of $1 \mathrm{mg} / \mathrm{kg}$ activated microglia, mice exposed to chronic low-dose MA showed little microglial activation $72 \mathrm{~h}$ after the last treatment and responded minimally when exposed to LPS or an additional MA injection [26]. This microglial response was accompanied by an attenuated central inflammatory cytokine response to LPS. The difference between our previous results and our current results lies in the MA dosing regimen; while our previous study was based on a pharmacological dose, the current study utilized a neurotoxic dosing schedule. This schedule has been shown to damage dopamine nerve terminals, promote glial activation, and increase proinflammatory cytokines $[7,36,37]$. Given the dramatic difference between the two doses and schedules, the difference in the respective elicited responses is not surprising. While we did observe MA-associated increases in IL- 6 and TNF $\alpha$ mRNA, these increases (with the exception of TNF $\alpha$ 


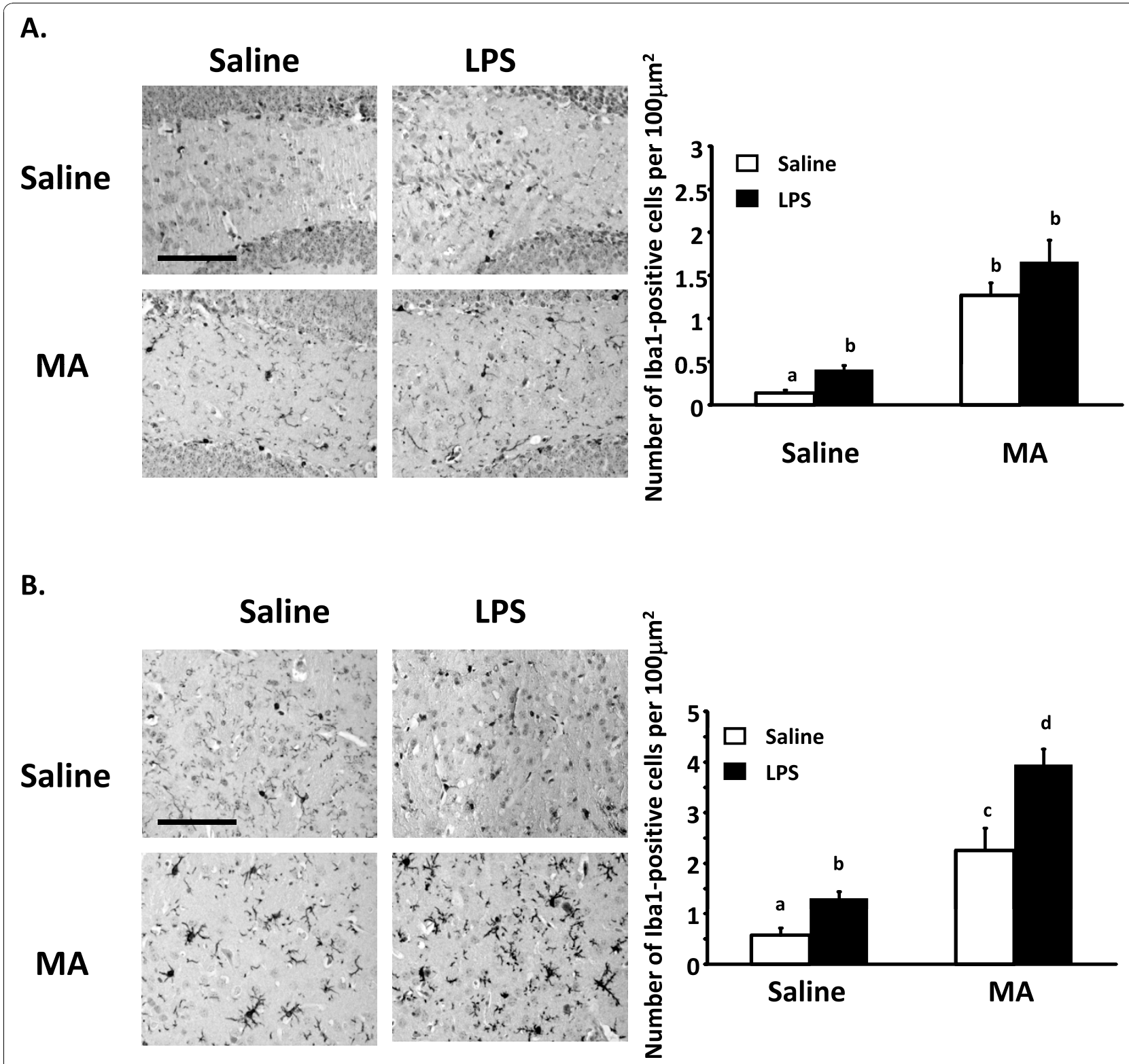

Figure 4 lba1 expression $\mathbf{4}$ h after LPS in mice exposed to methamphetamine. Immunohistochemical staining of Iba1 in the dentate gyrus of the hippocampus (A) and the striatum (B) of mice exposed to MA prior to LPS administration at 40x magnification. Mice were exposed to four i.p. injections of 0 or $5 \mathrm{mg} / \mathrm{kg}$ MA at $2 \mathrm{~h}$ intervals and then injected with $100 \mu \mathrm{g} / \mathrm{kg}$ LPS or saline $24 \mathrm{~h}$ after the first MA injection. Brains were collected $4 \mathrm{~h}$ after LPS administration. Scale bar $=100 \mu \mathrm{m}$. Bar graphs express number of Iba1-positive cells per $100 \mu \mathrm{m}^{2}$.

Table 1 Plasma cytokines $4 \mathrm{~h}$ after LPS in mice exposed to MA

\begin{tabular}{lccccccc}
\hline & \multicolumn{2}{c}{$\mathbf{0 ~} \mathbf{~ g} / \mathbf{k g}$ MA } & \multicolumn{2}{c}{$\mathbf{5} \mathbf{~ m g / k g ~ M A}$} & \multicolumn{1}{c}{$\mathbf{p}$} \\
\cline { 2 - 9 } & Saline & LPS & Saline & LPS & MA & LPS & MA $\times$ LPS \\
\hline IL-1 $\beta$ & $124.63 \pm 47.25$ & $253.4 \pm 47.48$ & $226.77 \pm 10.97$ & $135.57 \pm 12.7$ & 0.82 & 0.59 & $0.0078^{\#}$ \\
\hline IL-6 & $36.61 \pm 11.41$ & $662.74 \pm 426.8$ & $33.54 \pm 9.27$ & $1557.7 \pm 196.1$ & 0.08 & $0.006^{*}$ & 0.08 \\
\hline TNF $\alpha$ & $278.61 \pm 78.1$ & $501.02 \pm 106.5$ & $268.05 \pm 33.3$ & $225.49 \pm 32.7$ & 0.06 & 0.22 & 0.08 \\
\hline IL-10 & $107.89 \pm 28.2$ & $220.43 \pm 33.9$ & $111.0 \pm 10.57$ & $287.12 \pm 69.4$ & 0.42 & $0.005^{*}$ & 0.46 \\
\hline
\end{tabular}

Mice were given four injections of saline or MA $(5 \mathrm{mg} / \mathrm{kg})$ i.p. at $2 \mathrm{~h}$ intervals. Twenty-four hours after the first MA injection, mice were given either saline or LPS $(100 \mu \mathrm{g} / \mathrm{kg})$ and blood was collected at $4 \mathrm{~h}$ post-injection. ${ }^{*} \mathrm{p}<0.01$, different from saline controls. ${ }^{\sharp} \mathrm{p}<0.01 \mathrm{MA} \times$ LPS interaction. 
mRNA in the striatum) were small. This is most likely due to the time point of measurement $(4 \mathrm{~h}$ post-LPS but $16 \mathrm{~h}$ after the first MA administration). Possibly, had cytokines been measured soon after MA-exposure, there would have been a MA-related increase. Taken together, it is possible that MA differentially affects the microglial response to a peripheral immune stimulus, either inhibiting or exacerbating the central immune response depending on the dose and schedule.

Peripheral immune stimulation induces cytokines in both the brain and the periphery. In the present study, there was a trend toward MA-related differences in LPS-induced plasma cytokines, indicating that MA influences not only the central cytokine response, but the peripheral response as well. This was particularly true for IL-1 $\beta$, in which there was a MA $\times$ LPS interaction whereby MA alone increased IL- $1 \beta$ but also inhibited the LPS-induced increase in the cytokine. A similar but not significant effect was observed for plasma TNF $\alpha$. This suggests that while MA administration heightened the central inflammatory response, it concomitantly suppressed the inflammatory cytokine response in the periphery. This differs from our previous study which showed that, while acute administration of $1 \mathrm{mg} / \mathrm{kg}$ MA increased plasma IL-1 $4 \mathrm{~h}$ post-injection, neither acute nor repeated low-dose MA administration interfered with the LPS-induced increase in plasma cytokines [26]. As in the case of microglia responses, the difference is most likely due to differences in the dose and dosing schedule used. However, the current results are generally consistent with other reports showing suppressive effects of MA on peripheral immune function [21,22]. IL-1 $\beta$ is an important cytokine involved in fever. Both peripheral and central administration of IL- $1 \beta$ induces fever $[38,39]$ and blocking IL- $1 \beta$ attenuates the fever response to LPS $[40,41]$. Given the bidirectional nature of communication between periphery and brain and the heightened inflammatory environment of the MAexposed brain, it is possible that the MA-related decrease in LPS-induced IL-1 $\beta$ plasma is an adaptive mechanism that may serve to downregulate signals from the periphery in response to the heightened neuroinflammatory signals in the CNS. Taken together, our data suggest that MA alters the production of both inflammatory and anti-inflammatory cytokines in the periphery while inducing a heightened inflammatory environment in the brain.

Peripheral immune stimulation activates brain microglia and LPS reliably induces cytokines in both the brain and the periphery, but it is this central cytokine response that is essential for the initiation of sickness behavior, which is an integrated, adaptive, and protective response to illness necessary for recovery and survival. MA use is associated with an increased prevalence of
HIV infection, hepatitis B and C, fungal infections, and possibly others [1-4]. Given the popularity of MA and its association with immune dysfunction even years after MA use has ceased, it is important to understand how MA influences the immune response. The potential that MA use can exacerbate the neuroimmune response to an invading pathogen presents a serious problem in the human population, since an optimal inflammatory response is necessary for survival and recovery. Furthermore, because neuroinflammation has been demonstrated to be an important mechanism involved in a number of CNS pathologies, it may be possible for MA abuse to exacerbate or hasten the progression of these diseases.

\section{Acknowledgements}

This research was supported by the NIH DA024443.

\section{Authors' contributions}

JBB designed and performed the experiments, analyzed the data, and wrote the manuscript. NLS designed and performed the experiments and edited the manuscript. RWJ oversaw the experimental design and edited the manuscript. All authors have read and approved the final version of the manuscript.

\section{Competing interests}

The authors declare that they have no competing interests.

Received: 9 September 2010 Accepted: 22 November 2010

Published: 22 November 2010

\section{References}

1. Halkitis PN, Parsons JT, Stirratt MJ: A double epidemic: crystal methamphetamine drug use in relation to HIV transmission among gay men. J Homosex 2001, 41(2):17-35.

2. Purcell DW, Parsons JT, Halkitis PN, Mizuno Y, Woods WJ: Substance use and sexual transmission risk behavior of HIV-positive men who have sex with men. J Subst Abuse 2001, 13(1-2):185-200.

3. Gonzales R, Marinelli-Casey P, Shoptaw S, Ang A, Rawson RA: Hepatitis C virus infection among methamphetamine-dependent individuals in outpatient treatment. J Subst Abuse Treat 2006, 31(2):195-202.

4. Miller $C L$, Kerr T, Fischer B, Zhang R, Wood E: Methamphetamine injection independently predicts hepatitis $C$ infection among street-involved youth in a Canadian setting. J Adolesc Health 2009, 44(3):302-304.

5. Cadet $J$, Jayanthi S, Deng X: Speed kills: cellular and molecular bases of methamphetamine-induced nerve terminal degeneration and neuronal apoptosis. Faseb J 2003, 17(13):1775-1788.

6. Yamamoto BK, Moszczynska A, Gudelsky GA: Amphetamine toxicities: classical and emerging mechanisms. Ann N Y Acad Sci 2010, 1187:101-121.

7. Thomas DM, Walker PD, Benjamins JA, Geddes TJ, Kuhn DM: Methamphetamine neurotoxicity in dopamine nerve endings of the striatum is associated with microglial activation. J Pharmacol Exp Ther 2004, 311(1):1-7.

8. Riddle EL, Fleckenstein AE, Hanson GR: Mechanisms of methamphetamine-induced dopaminergic neurotoxicity. Aaps J 2006, 8(2):E413-418

9. Sekine $Y$, Ouchi $Y$, Sugihara G, Takei N, Yoshikawa E, Nakamura K, Iwata $Y$, Tsuchiya KJ, Suda S, Suzuki K, et al: Methamphetamine causes microglial activation in the brains of human abusers. J Neurosci 2008, 28(22):5756-5761.

10. Goncalves J, Baptista S, Martins T, Milhazes N, Borges F, Ribeiro CF, Malva JO, Silva AP: Methamphetamine-induced neuroinflammation and neuronal dysfunction in the mice hippocampus: preventive effect of indomethacin. Eur J Neurosci 2010, 31(2):315-326. 
11. Fantegrossi WE, Ciullo JR, Wakabayashi KT, De La Garza R, Traynor JR, Woods JH: A comparison of the physiological, behavioral, neurochemical and microglial effects of methamphetamine and 3,4methylenedioxymethamphetamine in the mouse. Neuroscience 2008, 151(2):533-543.

12. Hozumi H, Asanuma M, Miyazaki I, Fukuoka S, Kikkawa Y, Kimoto N, Kitamura Y, Sendo T, Kita T, Gomita Y: Protective effects of interferongamma against methamphetamine-induced neurotoxicity. Toxicol Lett 2008, 177(2):123-129.

13. Thomas DM, Kuhn DM: Attenuated microglial activation mediates tolerance to the neurotoxic effects of methamphetamine. J Neurochem 2005, 92(4):790-797.

14. Flora G, Lee YW, Nath A, Hennig B, Maragos W, Toborek M: Methamphetamine potentiates HIV-1 Tat protein-mediated activation of redox-sensitive pathways in discrete regions of the brain. Exp Neurol 2003, 179(1):60-70.

15. Nakajima A, Yamada K, Nagai T, Uchiyama T, Miyamoto Y, Mamiya T, He J, Nitta A, Mizuno M, Tran MH, et al: Role of tumor necrosis factor-alpha in methamphetamine-induced drug dependence and neurotoxicity. $J$ Neurosci 2004, 24(9):2212-2225.

16. Numachi Y, Ohara A, Yamashita M, Fukushima S, Kobayashi $\mathrm{H}, \mathrm{Hata} H$ Watanabe H, Hall FS, Lesch KP, Murphy DL, et al: Methamphetamineinduced hyperthermia and lethal toxicity: role of the dopamine and serotonin transporters. Eur J Pharmacol 2007, 572(2-3):120-128.

17. Halladay AK, Kusnecov A, Michna L, Kita T, Hara C, Wagner GC: Relationship between methamphetamine-induced dopamine release, hyperthermia, self-injurious behaviour and long term dopamine depletion in BALB/C and C57BL/6 mice. Pharmacol Toxicol 2003, 93(1):33-41.

18. Lai YT, Tsai YP, Cherng CG, Ke JJ, Ho MC, Tsai CW, Yu L: Lipopolysaccharide mitagates methamphetamine-induced striatal dopamine depletion via modulating local TNF-alpha and dopamine transporter expression. J Neural Transm 2009, 116(4):405-415.

19. Saito M, Terada M, Kawata $T$, Ito $H$, Shigematsu $N$, Kromkhun $P$, Yokosuka M, Saito TR: Effects of single or repeated administrations of methamphetamine on immune response in mice. Exp Anim 2008, 57(1):35-43.

20. Yu Q, Montes S, Larson DF, Watson RR: Effects of chronic methamphetamine exposure on heart function in uninfected and retrovirus-infected mice. Life Sci 2002, 71(8):953-965.

21. Martinez LR, Mihu MR, Gacser A, Santambrogio L, Nosanchuk JD: Methamphetamine enhances histoplasmosis by immunosuppression of the host. J Infect Dis 2009, 200(1):131-141.

22. In SW, Son EW, Rhee DK, Pyo S: Methamphetamine administration produces immunomodulation in mice. J Toxicol Environ Health A 2005, 68(23-24):2133-2145.

23. Maier SF, Goehler LE, Fleshner M, Watkins LR: The role of the vagus nerve in cytokine-to-brain communication. Ann N Y Acad Sci 1998, 840:289-300.

24. Rivest S: Molecular insights on the cerebral innate immune system. Brain Behav Immun 2003, 17(1):13-19.

25. Block ML, Hong JS: Microglia and inflammation-mediated neurodegeneration: multiple triggers with a common mechanism. Prog Neurobiol 2005, 76(2):77-98.

26. Buchanan JB, Sparkman NL, Johnson RW: Methamphetamine sensitization attenuates the febrile and neuroinflammatory response to a subsequent peripheral immune stimulus. Brain Behav Immun 2010, 24(3):502-511.

27. Ito D, Imai Y, Ohsawa K, Nakajima K, Fukuuchi Y, Kohsaka S: Microgliaspecific localisation of a novel calcium binding protein, lba1. Brain Res Mol Brain Res 1998, 57(1):1-9.

28. Ito D, Tanaka K, Suzuki S, Dembo T, Fukuuchi Y: Enhanced expression of Iba1, ionized calcium-binding adapter molecule 1, after transient focal cerebral ischemia in rat brain. Stroke 2001, 32(5):1208-1215.

29. Qin L, Wu X, Block ML, Liu Y, Breese GR, Hong JS, Knapp DJ, Crews FT: Systemic LPS causes chronic neuroinflammation and progressive neurodegeneration. Glia 2007, 55(5):453-462.

30. Sandhir R, Onyszchuk G, Berman NE: Exacerbated glial response in the aged mouse hippocampus following controlled cortical impact injury. Exp Neurol 2008, 213(2):372-380.

31. Graham DL, Noailles PA, Cadet JL: Differential neurochemical consequences of an escalating dose-binge regimen followed by singleday multiple-dose methamphetamine challenges. J Neurochem 2008, 105(5):1873-1885.
32. Danaceau JP, Deering CE, Day JE, Smeal SJ, Johnson-Davis KL, Fleckenstein AE, Wilkins DG: Persistence of tolerance to methamphetamine-induced monoamine deficits. Eur J Pharmacol 2007, 559(1):46-54

33. Cadet JL, Krasnova IN, Ladenheim B, Cai NS, McCoy MT, Atianjoh FE: Methamphetamine preconditioning: differential protective effects on monoaminergic systems in the rat brain. Neurotox Res 2009, 15(3):252-259.

34. Stephans S, Yamamoto B: Methamphetamines pretreatment and the vulnerability of the striatum to methamphetamine neurotoxicity. Neuroscience 1996, 72(3):593-600.

35. Johnson-Davis KL, Fleckenstein AE, Wilkins DG: The role of hyperthermia and metabolism as mechanisms of tolerance to methamphetamine neurotoxicity. Eur J Pharmacol 2003, 482(1-3):151-154.

36. Thomas DM, Dowgiert J, Geddes TJ, Francescutti-Verbeem D, Liu X, Kuhn DM: Microglial activation is a pharmacologically specific marker for the neurotoxic amphetamines. Neurosci Lett 2004, 367(3):349-354.

37. Sriram K, Miller DB, O'Callaghan JP: Minocycline attenuates microglial activation but fails to mitigate striatal dopaminergic neurotoxicity: role of tumor necrosis factor-alpha. J Neurochem 2006, 96(3):706-718.

38. Buchanan JB, Peloso E, Satinoff E: Influence of ambient temperature on peripherally induced interleukin-1 beta fever in young and old rats. Physiol Behav 2006, 88(4-5):453-458

39. Plata-Salaman CR, Peloso E, Satinoff E: Interleukin-1beta-induced fever in young and old Long-Evans rats. Am J Physiol 1998, 275(5 Pt 2): R1633-1638.

40. Cartmell $T$, Luheshi GN, Rothwell NJ: Brain sites of action of endogenous interleukin-1 in the febrile response to localized inflammation in the rat. J Physiol 1999, 518(Pt 2):585-594.

41. Luheshi G, Miller AJ, Brouwer S, Dascombe MJ, Rothwell NJ, Hopkins SJ: Interleukin-1 receptor antagonist inhibits endotoxin fever and systemic interleukin-6 induction in the rat. Am J Physiol 1996, 270(1 Pt 1):E91-95.

doi:10.1186/1742-2094-7-82

Cite this article as: Buchanan et al:: A neurotoxic regimen of methamphetamine exacerbates the febrile and neuroinflammatory response to a subsequent peripheral immune stimulus. Journal of Neuroinflammation 2010 7:82

\section{Submit your next manuscript to BioMed Central and take full advantage of:}

- Convenient online submission

- Thorough peer review

- No space constraints or color figure charges

- Immediate publication on acceptance

- Inclusion in PubMed, CAS, Scopus and Google Scholar

- Research which is freely available for redistribution

Submit your manuscript at www.biomedcentral.com/submit
C Biomed Central 